\title{
Imaginación práctica como posibilitadora de la racionalidad práctica
}

\author{
GUSTAVO PEREIRA* \\ Universidad de la República (Uruguay) \\ gustavofelper@gmail.com
}

\begin{abstract}
Resumen
El uso del término imaginación remite a un cierto tipo de actividad mental que en su formulación más básica refiere a la capacidad humana para crear imágenes en ausencia de lo representado, es decir, para representarnos objetos o estados de cosas que están ausentes, y a la capacidad para crear imágenes a partir de otras que ya se poseen. Esta formulación permite dar cuenta de una amplia gama de experiencias humanas que van desde la creación artística y la innovación técnica hasta la anticipación de posibles escenarios en los que intervenir. En particular voy a centrarme en un uso específico de la imaginación que denominaré imaginación práctica y que consiste principalmente en la anticipación contrafáctica de posibles estados de cosas resultantes de nuestras acciones. A partir de esto sostendré la existencia de una relación interna entre imaginación práctica y racionalidad práctica, en virtud de la cual la primera oficia de posibilitadora de la segunda. Para ello relevaré cuatro formas de ejercicio de la racionalidad práctica que han sido tematizadas a lo largo de la historia de la filosofía: la ética, la moral, la política y la legal.
\end{abstract}

Palabras clave: imaginación práctica, racionalidad práctica, imaginación contrafáctica, vida práctica.

\section{Practical imagination as enabling practical rationality}

\begin{abstract}
The use of the term imagination refers to a certain type of mental activity that in its most basic formulation refers to the human capacity to create images in the absence of what is represented, that is, to represent objects or states of things that are absent, and the ability to create images from others that are already possessed by the agent. This formulation allows to account for a wide range of human experiences ranging from artistic creation and technical innovation to the anticipation of possible scenarios in which to intervene. In particular, I will focus on a specific use of the imagination that I will call practical imagination and that consists mainly in the counterfactual anticipation of possible states of affairs resulting from our actions. From this perspective I will sustain the existence of an internal relation between practical imagination and practical rationality, by virtue of which the first enables the second. To do this, I will highlight four types of practical rationality that have been thematized throughout the history of philosophy: ethical, moral, political and legal rationality.
\end{abstract}

Keywords: practical imagination, practical rationality, counterfactual imagination, practical life.

* $\quad$ Doctor en Filosofía por la Universidad de Valencia. Profesor Titular y Director del Departamento de Filosofía de la Práctica de la Facultad de Humanidades y Ciencias de la Educación de la Universidad de la República. Es autor de los libros Medios, capacidades y justicia distributiva (2004), ¿Condenados a la desigualdad extrema? (2007), Las voces de la igualdad (2010), Elements of a Critical Theory of Justice (2013) y editor junto con Adela Cortina de Pobreza y libertad (2009).

Recibido: 16/Noviembre/2017 - Aceptado: 17/Enero/2018 
El uso del término imaginación da cuenta de una categoría que ha sido utilizada a lo largo de la historia del pensamiento para describir cierto tipo de actividad mental que en su formulación más básica refiere a la capacidad humana para crear imágenes en ausencia de lo representado, es decir, para representarnos objetos o estados de cosas que están ausentes, y a la capacidad para crear imágenes a partir de otras que ya se poseen. Al hablar de imaginación referimos a una amplia gama de experiencias humanas, tales como la capacidad para anticipar un mundo más justo, para imaginar otras formas de vida que la que llevamos adelante, para tener fantasías, para la creación artística y científica, o para la innovación técnica, entre otras. Detrás de estas experiencias que contempla esta formulación básica de la imaginación se encuentran las distintas funciones que ella tiene en la vida humana, tales como el hacer posible la experiencia y el conocimiento, la deliberación, la reflexión y la autonomía, al igual que la evaluación crítica de prácticas en las que nos desempeñamos o de estados de cosas en los que vivimos, así como también posibilita nuestras creencias y valores, las relaciones interpersonales que tenemos, y también ciertas emociones. Por esto es que es posible afirmar que la imaginación oficia como condición de posibilidad de un conjunto de rasgos que nos permiten reconocernos como humanos, y muy especialmente como personas, a tal punto que podría ser considerada como el rasgo constitutivo más básico de nuestra humanidad. Sin la capacidad de hacer presentes estados de cosas ausentes, no solamente no podríamos representarnos el mundo tal cual lo conocemos, sino que tampoco podríamos autocomprendernos como seres reflexivos capaces de autodeterminarnos y de construir, criticar o reconfigurar el mundo social que nos rodea. Esto último depende de la característica distintiva de la imaginación, además de la capacidad de hacer presente lo ausente, de poder concebir una imagen a partir de otras, que es lo que permite representar y concebir estados de cosas no existentes como posibles y realizables. A su vez, y como ya se adelantó, el campo de aplicación del concepto de imaginación es sumamente vasto, ya que con el mismo concepto podemos referir entre otros a la creación artística, a la innovación tecnológica, a la creación científica, a la creación publicitaria, a la ejecución artesanal y laboral, a la anticipación de posibles órdenes sociales y a la figuración de un nuevo plan de vida que queremos asumir.

El interés de este trabajo en la imaginación es en una especificación muy particular del concepto, en aquella que es parte del ejercicio de la racionalidad práctica, por lo que bien podríamos hablar de una imaginación práctica. Voy a sostener que esta imaginación práctica es principalmente contrafáctica y que en tanto se encuentra internamente asociada a la racionalidad práctica tiene la particularidad de especificarse al igual que esta última en diferentes contextos prácticos y de hacer posible el ejercicio 
de tal racionalidad. Para desarrollar este punto a continuación presentaré lo distintivo de la imaginación práctica en tanto imaginación contrafáctica, para a continuación desarrollar su especificación en cuatro contextos prácticos, el ético, el moral, el político y el legal, en donde presentaré la forma en que la imaginación oficia de posibilitadora de nuestra racionalidad práctica y nuestra vida práctica.

\section{IMAGINACIÓN PRÁCTICA COMO IMAGINACIÓN CONTRAFÁCTICA}

La imaginación práctica entra en juego en la representación y anticipación de posibles escenarios en los que nos vemos a nosotros mismos realizando un curso de acción y viviendo las consecuencias del mismo, y a partir de esta anticipación es que tomamos nuestras decisiones y actuamos. En virtud de esto la imaginación práctica es principalmente una imaginación contrafáctica (Stalnaker, 1984; Mackenzie, 2000) y se diferencia de la imaginación creativa que podemos constatar en las obras artísticas o en el diseño de experimentos científicos o en los procesos de innovación tecnológica. En estos casos, si bien el elemento contrafáctico está presente, ocupa un lugar subordinado frente a la creatividad que es su rasgo distintivo, mientras que en la imaginación práctica lo distintivo es la primacía del rasgo contrafáctico articulado con nuestra historia vital y su proyección en el futuro. Por esto la imaginación práctica tiene un ejercicio acotado al campo de lo posible y realizable, y dentro de este marco es que pueden anticiparse escenarios en los que podemos realizar, por ejemplo, una transformación sustantiva de nuestro plan vital y abandonar la vida de profesor de la Universidad para dedicarnos a la restauración de muebles, o postular un conjunto de medidas que realicen radicalmente la justicia social como la cooperativización de los emprendimientos productivos o la renta básica universal. De esta realizabilidad y su conexión con nuestras experiencias antecedentes tanto colectivas como individuales es que depende que el ejercicio de la imaginación práctica pueda disparar procesos de justificación intrapersonal o interpersonal orientados a la realización de esos escenarios anticipados contrafácticamente. La imaginación práctica, entonces, se desempeña en la frontera entre lo real y lo posible, permitiéndole al individuo situarse en una perspectiva no actual en la que realiza una especie de simulación del mundo, es decir “(...) una recreación mental, un modelo, no alimentado por los datos de la percepción en tiempo real o de la memoria inmediata sobre los datos del mundo" (Broncano, 2009: 246).

La anticipación de posibles estados de cosas por parte de la imaginación práctica se encuentra fuertemente determinada por nuestra experiencia pasada, en la que alteramos contrafácticamente algunos aspectos de los 
hechos y situaciones que hemos vivido, de tal forma de realizar una representación mental de cómo tales hechos y situaciones podrían haber sido diferentes, y de esa forma la imaginación práctica oficia como un elemento dinamizador de nuestro aprendizaje práctico. A través de esta vuelta al pasado y la proyección de escenarios posibles en el futuro es que el aprendizaje práctico nos permite adquirir habilidades que van desde la adquisición de las destrezas necesarias para realizar diferentes tipos de actividades productivas, hasta aquellas que son necesarias para llevar adelante una buena vida, para desempeñarnos como agentes morales o para actuar como ciudadanos en nuestra comunidad política.

A su vez, esta imaginación contrafáctica está tan consustanciada con la vida práctica que, tal cual revela la investigación psicológica llevada adelante por Ruth Byrne, muchos de los diferentes aspectos que los individuos suelen modificar en sus representaciones mentales cuando vuelven contrafácticamente a hechos que habrían modificado, dan cuenta de elementos distintivos de la vida práctica, tales como acciones, obligaciones o emociones (Byrne, 2005: 5-9). Además de esto la evidencia empírica que maneja Byrne la lleva a afirmar que la mayoría de las personas no crea mundos contrafácticos milagrosos, como los que surgirían de imaginar que los romanos hubiesen tenido ametralladoras (Tetlock \& Parker, 2005; Mullen \& Markman, 2002); la tendencia cuando realizamos experimentos mentales es a focalizarse en las posibilidades contrafácticas y no en las imposibilidades, es decir, en aquellas que en algún momento fueron verdaderas posibilidades y no en cosas que dada la forma en que es el mundo nunca podrían haber ocurrido. Lo que se crea a través del pensamiento contrafáctico son posibles alternativas, y lo que es admisible dentro de lo que es o no posible depende de las creencias de las personas y de cuán cerca de los hechos se encuentran tales contrafácticos (Byrne, 2005: 10).

Esta imaginación práctica, además de articular el desarrollo de nuestras competencias para el juicio moral, está internamente ligada al ejercicio de la racionalidad práctica y por ello oficia como concepto clave para explicar la autonomía, la deliberación y la reflexión. La relación entre la imaginación y la racionalidad práctica está presente en el rol que juegan los condicionales en el razonamiento, estableciendo posibles relaciones entre eventos a través de conjeturas que los vinculan. Debido a esto es que la capacidad de ser racional y actuar racionalmente depende de nuestra capacidad de imaginar posibles estados de cosas o cursos de acción alternativos a los presentes. La imaginación, entendida como imaginación contrafáctica, permite manejar situaciones hipotéticas tanto en la reflexión individual como en el intercambio de argumentos que realizamos con otros en nuestra vida práctica, y su relación con la racionalidad reside en que los 
principios que subyacen a la racionalidad práctica son por una parte posibilitados por dicha imaginación, y por otra son los que guían las posibilidades que los individuos en su vida práctica hacen entrar en juego. Por lo tanto, si bien la imaginación práctica le da ingreso a un conjunto de posibilidades en el horizonte a los individuos que bajo un trasfondo de libertad se predisponen a actuar, esas posibilidades se encuentran fuertemente acotadas y reguladas por los principios de la racionalidad práctica, que a la vez son posibilitados por el ejercicio de la imaginación. De ahí que la ligazón interna entre imaginación y racionalidad práctica no solamente se debe a que es virtualmente imposible explicar la racionalidad práctica sin el ejercicio de esta imaginación, sino también a que la imaginación no puede operar dentro del terreno de la vida práctica sin la guía de los principios de la racionalidad práctica. A partir de esto es que, de la misma forma que puede diferenciarse a la racionalidad práctica en pragmática, ética, moral, política y legal ${ }^{1}$, algo similar puede hacerse con la imaginación. Recordemos que la racionalidad práctica puede diferenciarse a partir de su objeto y de la forma en que se actúa en el espacio social delimitado por el mismo. De ahí que cuando el objeto de la acción consiste en a) la elección de los mejores medios para alcanzar el conjunto de fines que adoptamos, estamos frente a la racionalidad pragmática, cuando tal objeto es b) el plan vital que decidimos abrazar para alcanzar lo que consideramos nuestra vida buena, entonces estamos ante la racionalidad ética, cuando el objeto consiste en c) los principios que regulan nuestra acción desde la perspectiva de los intereses de todos quienes podrían llegar a estar afectados, estamos ante la racionalidad moral, cuando el objeto es $d$ ) la forma de organización de las instituciones sociales que regulan la manera en que nos asignamos unos a otros las cargas y los beneficios de la cooperación social, estamos ante la racionalidad política, y cuando el objeto está constituido por e) las normas que establecen el respeto recíproco a partir de los rasgos más generales de una persona objetivado en protecciones y límites a nuestros fines, estamos frente la racionalidad legal.

En correspondencia con estas formas de ejercicio de la racionalidad práctica tenemos, entonces, formas de ejercicio de la imaginación práctica, por lo que será posible hablar de una imaginación pragmática que consiste en la forma en que nos representamos los mejores medios para alcanzar los fines que aspiramos a lograr, de una imaginación ética que consiste en

La diferenciación en estas cinco formas de especificación de la racionalidad práctica la he desarrollado previamente (Pereira, 2013) y la tomo de Habermas (2000) y Forst (2002; 2007). Un estudio detallado de la normatividad inherente a las distintas pretensiones de validez en juego es presentado por Baynes (2001). 
la forma que tenemos de representarnos a la luz de los valores que adoptamos qué deberíamos mantener, reforzar o reconfigurar en nuestro plan de vida para realizar lo que consideramos una vida buena, de una imaginación moral que consiste en la representación de un estado de cosas en el que todos los afectados llevarían adelante la norma que nos regula, de una imaginación política que consiste en la representación de formas de organización de las instituciones sociales en las que se contemplen igualitariamente los intereses de los ciudadanos y de una imaginación legal que consiste en la forma en que nos representamos las protecciones y límites que tenemos en tanto sujetos de derecho. De estas cinco formas de ejercicio de la imaginación, voy a concentrarme solamente en las que se corresponden con un ejercicio de la racionalidad práctica mediado por la intersubjetividad y eso implica excluir a la racionalidad pragmática; la razón para ello es que tanto esta forma de racionalidad como su correspondiente forma de imaginación se encuentran subordinadas a las otras formas de racionalidad y consecuentemente a las otras formas de imaginación, porque quienes proveen los fines para los que la racionalidad pragmática busca los mejores medios son los imperativos prudenciales, morales, políticos o legales. Por ello es que la racionalidad pragmática en tanto racionalidad de medios a fines tiene una normatividad que no es inherente a ella misma, sino que está dada por los imperativos a los que sirve (Korsgaard, 2008: 55-59 $)^{2}$. Esta función de "asesoramiento y asistencia" de la razón de medios a fines a los otros tipos de razón también queda de manifiesto en su ausencia a la hora de referimos a los imaginarios sociales que constituyen $\mathrm{y}$ articulan la forma en que nos autocomprendemos y muy especialmente estimulan el ejercicio de nuestra imaginación práctica. En tales imaginarios encontramos formas de autocomprendernos que dan cuenta del ejercicio de nuestra racionalidad e imaginación ética, moral, política y legal, pero no así de la pragmática. En los imaginarios sociales se objetiva nuestra autocomprensión como iguales, como seres que siempre son fines en sí mismos y nunca medios, es decir como seres con dignidad, como ciudadanos que tienen el poder de decidir la forma en que serán gobernados, o como sujetos de derecho que imponen límites y protecciones a sus fines, pero es muy difícil o imposible encontrar en estos imaginarios la mejor forma de alcanzar los fines que nos proponemos independizada de los fines que proveen la racionalidad ética, moral, política o legal. Solamente cuando la racionalidad pragmática está al servicio de las otras racionalidades es que

2 Esta función de "asesoramiento y asistencia" de la razón de medios a fines es lo que se encuentra detrás de la posición de Hume en su "slave passage" y que ha sido continuada en los no cognitivismos éticos contemporáneos, quienes al tener una versión restringida de la racionalidad solamente ponían de manifiesto este rol de la razón práctica. 
ocupa un lugar en nuestro imaginario, de tal forma de otorgarnos el mejor camino para lograr una buena vida, para lograr la mejor coordinación con otros, para justificar un principio moral, para alcanzar la mejor forma de participación en la vida política, o para establecer límites y protecciones a nuestros planes vitales, pero sin estos fines a quien servir la racionalidad pragmática queda fuera de los imaginarios sociales y por lo tanto fuera de la vida práctica. Su sentido en la vida práctica está determinado por su servicio a las otras formas de racionalidad práctica, y por ello lo que podría denominarse como imaginación pragmática no existe por sí, sino en su servicio a las otras imaginaciones. La imposibilidad de encontrar la dimensión pragmática en los imaginarios sociales, independizada de las otras formas de racionalidad, es una prueba del rol subsidiario que tiene esta forma de racionalidad con respecto a las otras formas de racionalidad práctica. Por ello es que al hablar de imaginación práctica voy a referirme a la imaginación ética, moral, política y legal, que son las que tienen un rol estructurador de nuestra vida práctica.

Estas formas de imaginación práctica se encuentran presentes en los trabajos de los filósofos que han desarrollado el concepto. En particular la imaginación ética y la moral son parte de la obra de quienes han sido las dos grandes referencias que establecieron el contexto de reflexión que permite hablar de la imaginación en estos términos: ellos son Aristóteles, en tanto primera formulación sistemática del concepto, y Kant, quien le asigna a la imaginación su carácter de posibilitadora de la experiencia y el conocimiento. A su vez, ambas perspectivas constituyen lo que Castoriadis denomina como el descubrimiento de la imaginación (Castoriadis, 2005: 150-151), y ofician como el mejor punto de partida para dar cuenta de lo que he denominado como imaginación práctica, por lo que a continuación me referiré a la contribución a la imaginación ética que realiza Aristóteles, y a la que Kant realiza a la imaginación moral. En cuanto a la imaginación política, su rasgo distintivo se presentará a partir de las distintas idealizaciones de un sistema político que desde Platón hasta nuestros días han estimulado el ejercicio de la imaginación contrafáctica, que tiene por objeto las formas de gobierno que elegimos para regular nuestra vida en común. Finalmente, la imaginación legal presenta una particular relación con la imaginación moral y la imaginación política, que ofician la primera de fuente normativa y la segunda de anticipación de diseños institucionales que permiten representar a los individuos como sujetos de derecho, y a partir de ello anticipar las protecciones externas necesarias para la persecución de sus fines. En conformidad con esto presentaré a la imaginación práctica en sus diferentes especificaciones como una forma de indicar su condición de posibilitadora de la racionalidad práctica y como concepto 
articulador de nuestra condición de sujetos autónomos, reflexivos y capaces de crítica.

\section{IMAGINACIÓN ÉTICA}

La imaginación práctica en su especificación como imaginación ética tiene como función representar potenciales estados de cosas en los que el agente anticipe diferentes cursos de acción que podría recorrer en la realización de lo que considera una buena vida, de esa forma es que contribuye a que el agente visualice la elección entre medios alternativos para alcanzar sus fines, o transformar, reforzar o ajustar los fines vitales que actualmente lo guían. Las representaciones que provee la imaginación se dan bajo un trasfondo de evaluación deliberativa, que posibilita que el agente reflexione sobre aquello que le otorga valor y sentido a la vida que quiere vivir. Esta forma de imaginación práctica que se corresponde con un tipo de racionalidad práctica, la racionalidad ética, tiene en Aristóteles a una de las figuras más representativas.

Aristóteles es a quien se le debe la primera formulación sistemática de la imaginación tal como la entendemos hasta el día de hoy, ya que, si bien en Platón se encuentran referencias al término fantasía, éstas son muy poco frecuentes y dispersas ${ }^{3}$. Aristóteles en el capítulo tercero de Acerca del alma presenta a la imaginación (fantasía) como una facultad del alma y al hacerlo distingue dos tipos de imaginación: la sensitiva y la deliberativa. La primera de ellas tiene lugar en los animales, mientras que la segunda solamente se da en el hombre y consiste en la elaboración de una imagen a partir de varias imágenes que posee el sujeto. En virtud de esto es que la imaginación inherente al hombre, es básicamente creativa y puede ser considerada como la facultad que origina una imagen mental a partir de elementos sensibles provenientes del mundo exterior o presentes en otras imágenes, en un proceso libre que, a su vez, es independiente del tiempo y la verdad.

La relevancia que tiene la imaginación para Aristóteles (1994: 434a 610, 249), y muy especialmente para la imaginación ética, se encuentra en que, como consecuencia de este rasgo de crear una imagen a partir de otras, le posibilita al intelecto calcular los medios que han de utilizarse para conseguir el fin de la acción; es decir, que la imaginación toma parte directamente en la deliberación. La imaginación permite la representación de posibles escenarios que no están presentes y que son considerados como

\footnotetext{
3 Platón (1985, Teeteto y Sofista) en los diálogos críticos sostiene que la imaginación es una combinación de doxa y aisthesis, es decir, de sensación combinada con pensamiento que lo lleva a advertir sobre la dependencia de la fantasía de los sentidos, que conduce a una forma de pensar basada en las apariencias.
} 
un posible futuro. A partir de ello es que el agente evalúa y se representa diferentes medios alternativos para realizar una acción que le permita alcanzar un fin propuesto, y en función de esto es que elige los medios que considera más apropiados. Esta es la función de la imaginación en el cálculo deliberativo, y es por ello que tiene una importancia decisiva en el ámbito de la praxis, es decir, en el de la deliberación acerca de lo que puede ser de otra manera.

También en el capítulo tercero de Acerca del alma, Aristóteles (1994: 224-225 [427b 14-18]) establece el lugar que ocupa la imaginación entre las facultades, diciendo que es una facultad distinta del sentido y del intelecto, que se alimenta de la sensación y vuelve posible el juicio, pero que no es ninguno de ellos ${ }^{4}$. Sin embargo, el mayor interés para el propósito de este trabajo se encuentra, además de lo ya indicado del capítulo 3 sobre la relevancia de la imaginación para la vida práctica, en el capítulo 7 , donde introduce la conexión de la imaginación con el intelecto. En este capítulo Aristóteles afirma que el alma discursiva utiliza imágenes, lo que afecta tanto a la actividad intelectual, como a la vida práctica; ambas actividades necesitan constantemente de la imaginación, por lo que la agencia humana, en tanto involucra tanto el conocimiento como la acción, no puede ser concebida sin la imaginación (Aristóteles, 1994: 234 [431a 14-17]). Sin la imaginación no es posible el pensamiento especulativo ni tampoco la deliberación sobre lo que puede ser de otra manera, es decir, cuando el hombre orientado a la acción "calcula y delibera comparando el futuro con el

\footnotetext{
4 Con respecto a esto, la imaginación se diferencia del inteligir porque opinar o realizar juicios no depende exclusivamente de nosotros y es por ello que podemos incurrir en la verdad o en el error; en el caso de la imaginación, ésta no puede ser verdadera o falsa ya que no depende de nada exterior al agente, y como solamente depende del propio agente, puede ser ejercida a voluntad y a partir de ello crear ficciones (Aristóteles, 1994: 225 [427b 16-21]), con la particularidad de que esas imágenes pueden ser ubicadas en el futuro o incluso ser intemporales.

También, según Aristóteles, la imaginación se diferencia del entendimiento con respecto al efecto que producen los objetos a los que refiere cada uno de ellos. En el caso del entendimiento cuando opinamos que algo es terrible experimentamos una fuerte impresión, pero cuando lo imaginamos tal impresión no se suscita, sino que lo experimentamos como quien contempla una pintura, debido a que son ficticios (Aristóteles, 1994: 225 [427b 23-24]).

Tampoco la imaginación es un sentido según Aristóteles, ya que el sentido siempre está en potencia o en acto (vista y visión), mientras que una imagen se puede dar sin que haya potencia y acto, tal como ocurre en los sueños. A esto cabe agregar que los sentidos siempre están presentes y disponibles para el agente, mientras que eso no sucede con la imaginación. $\mathrm{Y}$ al igual que en el caso del entendimiento las sensaciones al no depender exclusivamente del agente pueden ser verdaderas y falsas, mientras que en el caso de las imágenes tal cosa no es posible (Aristóteles, 1994: 226 [428a 5-16]).
} 
presente, como si estuviera viéndolo con ayuda de las imágenes o conceptos que están en el alma" (Aristóteles, 1994: 240 [431b 7-8]). Este cálculo deliberativo es el que conduce a la elección de los medios para conseguir el fin imaginado, evaluando para ello estados de cosas alternativos a los que alguien vive; a la vez el agente se representa por medio de la imaginación posibles consecuencias de un curso de acción, que le permiten anticipar no solamente la realización del fin que se propone sino el mejor camino para alcanzarlo. De esta forma es que la facultad de la imaginación pone en marcha los deseos y las acciones racionales del hombre.

A esto cabe agregar de nuestra parte y yendo más allá de lo afirmado por Aristóteles que el cálculo deliberativo no solamente es sobre los mejores medios para alcanzar un fin, sino que también lo es sobre los fines mismos que constituyen nuestro plan vital o nuestra idea de vida buena. Por ello es que la imaginación tiene una función central en la conformación de aquello que consideramos como suficientemente valioso como para ser perseguido en nuestra vida, ya que nos permite representarnos posibles escenarios en los que podemos anticipar cómo sería nuestra vida si lográsemos tales fines vitales y a partir de ello identificarnos con esos fines. La imaginación también nos permite revisar, ajustar, y eventualmente abandonar esos fines que en un momento son parte de nuestra idea de vida buena, pero que en otro pueden no serlo; la revisabilidad inherente a este ejercicio deliberativo que afecta a nuestro conjunto de fines es posible porque somos capaces de representarnos a nosotros mismos viviendo una vida estructurada a partir de ciertos fines, y tal representación oficia de una verdadera guía para la toma de decisiones vitales. Este ejercicio de imaginación contrafáctica que el agente lleva adelante como parte de la persecución de su plan de vida se realiza bajo el trasfondo de unas comprensiones compartidas que constituyen lo que se ha denominado como imaginarios. Estas comprensiones compartidas imponen los límites y el alcance de la imaginación ética, estableciendo cuáles son los posibles planes de vida que se podrían eventualmente llevar adelante, lo que está acotado históricamente y muy especialmente por aquello que entendemos como valioso de ser llevado adelante en nuestra vida. Estas coordenadas de ejercicio de la imaginación práctica están dadas por el trasfondo constituido por las comprensiones compartidas que vuelven posible nuestra vida práctica.

Si volvemos al pensamiento de Aristóteles, tenemos que a la relevancia que tiene la imaginación para la vida práctica, y especialmente para la conducción de una buena vida, él agrega que la prudencia, en tanto virtud de la parte deliberativa del alma, exige la colaboración de la imaginación; esto es así porque no sería posible que un agente actuara con prudencia si no fuese capaz de representarse las consecuencias de sus posibles cursos 
de acción. Por lo tanto, la toma de decisiones sobre los mejores medios para alcanzar nuestros fines, al igual que la conformación del conjunto de tales fines y el ejercicio prudente de las acciones que nos llevan a realizarlos, tienen un especial protagonismo de la imaginación, por lo que puede afirmarse que la imaginación para Aristóteles opera como el verdadero motor de la vida práctica.

Además de lo señalado, la imaginación ética tiene una especial contribución por parte de los estoicos, para quienes la práctica diaria era imprescindible en la construcción de hábitos que moldearan el carácter y permitieran adquirir sabiduría práctica. En particular Séneca enfatiza tanto la meditación cotidiana como la lucha diaria y permanente para adquirir buenos hábitos de conducta y pensamiento, de tal forma que esto funcione como una forma de prepararse para los posibles contratiempos que puede traernos la vida, y al anticiparlos y prepararse es que tales eventuales circunstancias se vuelven irrelevantes. Esta anticipación implica el uso de la imaginación contrafáctica, ya que para anticipar cómo los eventos pueden afectarlo, el individuo debe preguntarse cómo sería su sufrimiento ante una posible pérdida, o cómo podrían llegar a ser alteradas sus relaciones personales si tuviese un golpe de fortuna, y a partir de ese ejercicio de imaginación desarrollar su carácter. Esta preparación a través de la imaginación tiene a la anticipación de la muerte como la muestra más significativa de este ejercicio que lleva al individuo a actuar a partir de la representación de ese hecho que necesariamente afectará nuestra vida. Por lo tanto, la imaginación práctica ejercida como imaginación ética tiene la función de anticipar, es decir, de hacer presente el futuro, y especialmente de llevarnos a prepararnos para los posibles eventos que vayan a ocurrirnos, de tal forma que cuando acontezcan no serán algo absolutamente nuevo y podremos manejarlos con mayor sabiduría. En virtud de esto, nuestra felicidad depende de tal preparación para ello. Esto supone que la imaginación produce el acercamiento del futuro al presente y eso permite reducir el miedo, la ansiedad y el deseo que generan las nuevas posibles circunstancias en la medida en que ya han sido "vividas" (Séneca, Ep. 74, 345346).

Este ejercicio de la imaginación ética por parte de Séneca permite complementar el rol que le da Aristóteles, ya que si bien este último le otorga a la imaginación una especial función en el procedimiento por el cual se lleva adelante la toma de decisiones eligiendo los mejores medios para alcanzar los fines del individuo, y también para la conformación del conjunto de fines, el ejercicio de la imaginación que postula Séneca permite dotar de una orientación para la conformación del contenido tanto de los fines como de los medios para alcanzarlos a partir de la anticipación y de la preparación para lo que la fortuna pueda depararnos. Con esto no 
quiero asumir un compromiso con la forma en que es entendida la buena vida por parte de los estoicos, pero sí me parece imprescindible contar con su orientación para el logro de una buena vida.

A partir de lo anterior es posible afirmar que el ejercicio de la racionalidad ética, que tiene por objeto la buena vida, solamente es posible a partir de un ejercicio suficiente de imaginación ética, la cual oficia como supuesto de este tipo de racionalidad tal como ha sido presentado a partir de Aristóteles y los estoicos.

\section{IMAGINACIÓN MORAL}

La imaginación moral es parte, y en particular posibilita, el ejercicio de la racionalidad moral al representar potenciales estados de cosas en los que un conjunto de personas son reguladas por una norma que todos quienes son potencialmente afectados por ella podrían llegar a aceptar. Este ejercicio de imaginación contrafáctica especificado en las cuestiones morales está detrás de la ética kantiana, y sin duda la imaginación moral tiene en Kant a su figura más relevante; sin embargo, un antecedente inmediato a este ejercicio de la imaginación está presente en Hume. Cabe aclarar que tanto en el caso de Hume como en el de Kant, al hablar de imaginación práctica entendida como imaginación contrafáctica, no se está apelando al uso que ellos hacen de la imaginación, sino a la forma en que la ponen en juego cuando hablan de la moralidad, es decir de los juicios, normas y principios que regulan nuestra conducta en términos universales. Esto puede verse, en el caso de Hume (1992: 581, 771), en su forma de entender la idea del espectador prudente o juicioso, que es una perspectiva desde la cual justificar la coincidencia en nuestros juicios morales independientemente de las variaciones en la simpatía que tenemos hacia otros en diferentes circunstancias. Este es un "punto de vista más estable y general" que nos posibilita formular "un juicio más constante", de tal manera que "en nuestros razonamientos nos situamos siempre en él, con independencia de nuestra real situación en ese momento" (Hume, 1992: 582, 772773). Al adoptar este punto de vista, los juicios morales de los individuos se equiparan, y ello es el resultado de un ejercicio de imaginación práctica que contrafácticamente nos coloca más allá de la situación en la que realmente nos encontramos y nos permite asumir este "punto de vista más estable y general" y en virtud de ello emitir los juicios propios de esa perspectiva. El punto de vista del espectador juicioso, entonces, conduce al agente a emitir juicios morales como si estuviese en una situación en la que no sería afectado por las variaciones que nos imponen las diferentes afinidades que tenemos con las otras personas con quienes nos relacionamos. 
De esta forma es que Hume propone un punto de vista moral a partir de un ejercicio contrafáctico de imaginación.

Algo similar sucede en Kant, pero como en su obra la imaginación tiene un rol considerablemente más amplio que el que se ha establecido para la imaginación práctica, es preciso acotar con precisión a qué nos estamos refiriendo con imaginación moral dentro de las funciones que Kant le otorga a esta facultad. En tal sentido, la imaginación como posibilitadora de la experiencia y el conocimiento en tanto establece la conexión entre la intuición y las categorías al proveer el esquema que hace posible la aplicación de la categoría al fenómeno (Kant, 2010: 170) se encuentra fuera del alcance de lo que se ha denominado como imaginación práctica.

Los rasgos de la imaginación práctica tal como se la ha presentado, aparecen en forma primaria en la explicitación de las funciones de la imaginación que Kant hace en la Antropología. Al respecto afirma que dentro de las funciones que desempeña la imaginación hay una especialmente relevante y consiste en la facultad de representar intencionalmente lo pasado, es decir, recordar, y también la facultad de representar un estado de cosas como futuro, es decir, prever (Kant, 1991: 34). Estas dos facultades, señala Kant, en tanto sensibles se fundan en la asociación de las representaciones del pasado y el futuro del sujeto con el presente, “(...) esto es, para enlazar lo que ya no es con lo que todavía no es, por medio de lo que es presente, en una experiencia coherente" (Kant, 1991: 91). De esta forma puede decirse que la imaginación opera como posibilitadora del recordar y del prever, y estas dos facultades a su vez vuelven posible la representación de escenarios que podrían haber sido y a partir de ello que podrían llegar a ser. Esa "experiencia coherente" a la que se refiere Kant, establece la continuidad entre el pasado y el futuro del agente, a través de las posibles acciones que vaya a realizar. Por lo tanto, una eventual toma de decisiones reflejará aquello que el sujeto ha vivido y con lo que se identifica, o lo que ha vivido y con lo que no se identifica, de tal forma de tomar sus experiencias pasadas como punto de partida y proyectarlas hacia el futuro para decidir qué es lo mejor para su vida.

La relevancia del recordar y del prever, en tanto posibilitados por la imaginación, son parte del aprendizaje práctico de un individuo que a la vez le permiten tomar decisiones con respecto a su futuro, de tal forma de modificar la situación que lo afecta o continuar manteniéndola. De esta forma, y yendo más allá de lo afirmado por Kant, es que puede enfatizarse que la imaginación toma parte en los procesos de evaluación y eventual crítica de los estados de cosas que nos afectan al permitirnos representarnos otros estados de cosas como alternativos o reforzar los actuales a partir de la comparación con otros. 
Hasta el momento, la imaginación en Kant, si bien se acerca a lo que se ha indicado como una imaginación contrafáctica, que sería el rasgo distintivo de la imaginación práctica, se encuentra circunscripta a lo que sería la imaginación ética, es decir, aquella que posibilita y se ejerce conjuntamente con la racionalidad que tiene por objeto la toma de decisiones que hacen a la vida buena. Sin embargo, en Kant es posible encontrar un ejercicio de la imaginación sustancialmente más comprehensivo que el de la imaginación ética y es su ejercicio en términos morales, que si bien la contempla, culmina en un tipo de imaginación que descentra la posición del sujeto al requerir no solamente lo que es relevante para realizar el propio plan vital y la felicidad del sujeto, sino lo que todos podrían llegar a acordar o querer. La imaginación moral hace posible la representación de máximas que aspiran a tener validez universal, y por lo tanto contribuye sustantivamente al ejercicio de la racionalidad moral.

Esta afirmación requiere ser explicada con más detalle, ya que Kant no hace uso explícito de la imaginación cuando da cuenta de la acción a partir de los principios, que en tanto representación de la ley, nos mueven a actuar debido a que somos seres racionales. Recordemos que la acción supone la representación de principios que constriñen la voluntad, que son denominados mandatos y su fórmula son los imperativos. Kant afirma que es " $(. .$.$) prácticamente bueno lo que determina la voluntad por medio de$ representaciones de la razón y, consiguientemente, no por causas subjetivas, sino objetivas, esto es, por fundamentos que son válidos para todo ser racional como tal" (Kant, 1990: 60). El argumento de Kant prosigue en forma ampliamente conocida, introduciendo dos formas en que los imperativos mandan, esto es, hipotética y categóricamente, siendo que el imperativo hipotético representa la necesidad práctica de una acción como medio para algo más, y el categórico es el que representa a una acción como buena en sí, sin referencia a otro fin; estas últimas serían las acciones morales, mientras que bajo las primeras caerían las acciones de sagacidad y prudenciales. Claramente en el argumento la imaginación no está presente, pero la pregunta que surge es qué es lo que hace posible la representación de la razón y su determinación de la voluntad. Apelar como respuesta a la imaginación entendida como imaginación contrafáctica tiene la ventaja de justificar que en las formulaciones tanto de los imperativos hipotéticos como del categórico, el agente realiza un ejercicio de anticipación de escenarios potenciales, es decir, de experimentos mentales que involucran la adecuación de ciertos medios a los fines que el agente persigue en el caso de los imperativos hipotéticos, tanto técnicos como pragmáticos, y que apelan a la universalidad en el caso del imperativo categórico, que es el único incondicionado y por ello moral. Especialmente las distintas fórmu- 
las del imperativo categórico suponen a un sujeto realizando el experimento mental de querer que su máxima se vuelva ley universal (obra sólo según una máxima tal que puedas querer al mismo tiempo que se torne ley universal (Kant, 1990: 72), obra como si la máxima de tu acción debiera tornarse, por tu voluntad, ley universal de la naturaleza (Kant, 1990: 73) ), o realizando el experimento mental de representarse la acción que va a realizar y si ésta toma como medio o como fin en sí mismo a la humanidad (obra de tal modo que uses la bumanidad, tanto en tu persona como en la persona de cualquier otro, siempre como fin al mismo tiempo y nunca solamente como un medio (Kant, 1990: 84) ). Planteado de esta forma el rol de la imaginación parece claro; especialmente queda de manifiesto en el "como si" de la segunda formulación que conduce a pensar en una anticipación de un posible escenario que debe hacer el agente para orientar su acción. Y el apelar a esta cláusula es reiterado cuando se afirma "(...) todo ser racional debe obrar como si fuera por sus máximas siempre un miembro legislador en el reino universal de los fines. El principio formal de esas máximas es: “obra como si tu máxima debiera servir al mismo tiempo de ley universal —de todos los seres racionales-" (Kant, 1990: 98). Esto induce a pensar que la imaginación, entendida como imaginación contrafáctica, es la que posibilita que el agente se represente y anticipe aquello que Kant presenta en lo que sigue al "como si”, es decir, que por la propia voluntad la máxima se torne en ley universal, o que fuese un legislador del reino de los fines ${ }^{5}$.

De esta forma puede verse que en Kant la imaginación, además de posibilitar la experiencia y el conocimiento, está presente en las distintas manifestaciones de la imaginación práctica, esto es en la anticipación de posibles estados de cosas inherentes al ejercicio de la racionalidad práctica a través de los imperativos. Si bien en el caso de los imperativos hipotéticos no existe mayor novedad debido a que en Aristóteles ya encontramos una perspectiva coincidente en lo que hace a la imaginación ética como posibilitadora de la deliberación y de la prudencia, lo que sí es una contribución altamente significativa es lo que se ha denominado como imaginación moral, que hace a la representación de la ley moral, y muy especialmente a la anticipación y representación de posibles estados de cosas a través de los experimentos mentales requeridos para el ejercicio del impe-

\footnotetext{
5 Agradezco especialmente a María Julia Bertomeu quien me sugirió esta forma de entender la imaginación moral en la Fundamentación de la metafísica de las costumbres. Una forma similar de entender este ejercicio de imaginación moral en el procedimiento del Imperativo categórico puede verse en las Lecciones sobre la bistoria de la filosofía moral de John Rawls (2001: 185-6).
} 
rativo categórico. Esta imaginación moral oficia de posibilitadora de la racionalidad moral como se ha mostrado en el rol que juega en la operativa del imperativo categórico.

\section{IMAGINACIÓN POLÍTICA}

La imaginación política probablemente sea la que a lo largo de la historia ilustra en forma más clara el ejercicio de imaginación contrafáctica, propio de la imaginación práctica. La formulación de una estructura de gobierno sustancialmente diferente a la que regula a los miembros de una comunidad política es lo que ha caracterizado a las diferentes transformaciones que se han ido sucediendo a lo largo de la historia. En estos diferentes hitos, la anticipación contrafáctica de formas de gobierno, diseños institucionales o medidas específicas han estimulado a los ciudadanos a imaginarse cómo sería la vida política de su comunidad bajo estas posibles circunstancias, y los ejemplos van desde el gobierno de los sabios y la sociedad sin clases, a medidas mucho más específicas como el voto universal y la renta básica universal, pasando por la enorme tradición contractualista.

En este caso particular de la imaginación práctica, al igual que en la ética y la moral, los agentes se representan estados de cosas posibles, y por ello es que son capaces de anticipar formas de gobierno, ordenamientos institucionales y políticas públicas que pueden oficiar de guía para la transformación, el reforzamiento o reconfiguración de las formas en que su comunidad política es regulada. Como ya se indicó, el ejercicio de la imaginación práctica se lleva adelante bajo el trasfondo de comprensiones compartidas, que no solamente hacen posible nuestra vida social, sino que establecen los límites y el alcance del ejercicio de nuestra imaginación práctica. Estas comprensiones compartidas, que se han denominado imaginarios sociales, también son afectadas por las distintas teorías que los penetran y los moldean de diferentes formas y con diferentes intensidades dependiendo del tipo de imaginación práctica de la que se trate. En el caso particular de la imaginación política, la incidencia de las teorías políticas tiene un protagonismo tal en su articulación y eventual reconfiguración, que se da una relación de fuerte asimetría con respecto a las otras formas de imaginación práctica. Si bien tanto en la imaginación ética como en la moral las distintas teorías que a lo largo de la historia han incidido en la forma en que entendemos cómo debemos vivir y cómo debemos actuar moralmente tienen una presencia significativa, en el caso de la imaginación política parecería que es imposible disociar su ejercicio de las representaciones que nos proveen las teorías. Puede decirse que en la imaginación ética y moral la teoría llega como una respuesta al comportamiento que 
reconocemos en nuestra vida social, reforzándolo, sistematizándolo, ajustándolo o colocándolo en una nueva luz a través de los imaginarios sociales que compartimos, mientras que en el caso de la imaginación política se da la situación contraria, la teoría llega primero y a través del imaginario social cumple una función de guía y anticipación de nuestro comportamiento. La forma que tenemos de entender nuestra condición de ciudadanos, la forma en que debemos gobernarnos, los límites al poder del Estado, los mínimos de justicia a garantizar, entre muchos otros aspectos de nuestra imaginación política han sido provistos por teorías políticas que de una u otra forma han anticipado contrafácticamente estos aspectos. En este hecho en el que se manifiesta la significativa incidencia de la teoría en el imaginario político, radica la principal diferencia con la imaginación ética y moral, en las que tal incidencia es considerablemente menor o secundaria con respecto a las prácticas ya compartidas.

La particularidad del ejercicio de la imaginación política consiste, entonces, en la representación y anticipación de un conjunto de instituciones que regulan la forma en que se toman las decisiones que afectan a una comunidad política y la forma en que los ciudadanos nos asignamos unos a otros cargas y beneficios resultantes de la cooperación social. Esta representación depende del imaginario social compartido en su especificación como imaginario político, y por ello la tradición de las comunidades políticas establece los parámetros que hacen posible imaginar, a través de su proyección y anticipación contrafáctica, cómo deberían ser conformadas, reafirmadas o reconfiguradas tales instituciones. Por lo tanto, la imaginación política proyecta al futuro lo que hace presente del pasado en una continuidad signada por la coherencia que los miembros de esa comunidad se encargan de cuidar y asegurar a través de la interpretación de las estructuras y relaciones sociales que los han regulado. De esta forma la imaginación política a la vez que posibilita el ejercicio de la racionalidad política, también establece los límites para su ejercicio. Esto es posible porque la imaginación política remite a una comprensión colectiva compartida, objetivada como imaginario político, que establece los límites y el alcance del ejercicio de esta forma de imaginación y en virtud de ello oficia de punto de partida desde el cual proyectar posibles transformaciones, reconfiguraciones o procesos de crítica social. Esto último se explica porque solamente tiene sentido la crítica o una propuesta transformadora en la medida en que conecta con ese trasfondo de creencias y valores compartidos; si esto no se logra y la imaginación política rompe con el ancla de la comprensión compartida que le da sentido a su ejercicio, simplemente puede terminar postulando visiones que tengan poca o nula relevancia para estimular la vida pública de una sociedad. Por lo tanto, la crítica es socialmente 
relevante siempre que mantenga una cierta distancia entre la realidad cuestionada y lo que oficia de punto de vista desde el cual formularla; si esa distancia es excesiva la crítica pierde su foco al caer en una posición que difícilmente pueda ser vinculante para el resto de los miembros de la comunidad; si esa distancia no es suficiente la crítica simplemente no se suscita. La imaginación política, a partir del trasfondo del imaginario compartido, no solamente le da sentido y hace posible nuestras prácticas, sino también establece un rango de posibilidades de lo que puede concebirse como forma de organización política; dentro de estas posibilidades es que tiene lugar la crítica y la posible transformación de las estructuras y relaciones sociales que estructuran las instituciones sociales.

Sin embargo, es preciso ser muy enfático en que el ejercicio de la imaginación política no está solamente orientado a la crítica social o a la anticipación de sociedades que transformen radicalmente nuestras actuales estructuras y relaciones sociales; la imaginación política también está presente en resultados sociales que son o reproductivos o regresivos, ya que en casos tales como el desmantelamiento de la protección social de los sectores más vulnerables, quien decide tal cosa está imaginando cómo la sociedad se beneficiará con ello, o quien se involucra en un enfrentamiento bélico imagina tal estrategia como la mejor forma de defender su nación o los valores y creencias constitutivas de ella. Esto está en juego tanto en los casos de los gobernantes que toman decisiones que afectan a los ciudadanos, como en el caso de los ciudadanos mismos que legitiman tales decisiones en procesos de justificación pública. Las posibles interpretaciones del imaginario político que comparte una sociedad puede llevarla a tener compromisos con posiciones que a lo largo de un período de tiempo pueden entrar en contradicción o conflicto pero que en última instancia remiten a una interpretación básica compartida; cuando estas interpretaciones son sustancialmente diferentes de la autocomprensión compartida en el imaginario político y esto se perpetúa a lo largo del tiempo, entonces será posible hablar de una reconfiguración o transformación del imaginario político mismo y habrá una comprensión compartida basada en nuevas creencias y valores. Las diferentes posibles reconfiguraciones son parte de la sensibilidad histórica que tienen tanto los imaginarios como sus interpretaciones a la forma en que las distintas posiciones entran en escena en los procesos de discusión y justificación pública. En estos procesos, como ya se indicó, las distintas contribuciones teóricas juegan un rol fundamental; recordemos que una de las razones más importantes para que el libertarismo, que parecía estar muerto y sepultado en la década del sesenta, se convirtiera en una posición política altamente influyente a partir de los gobiernos de Reagan y Thatcher, fue su articulación en una nueva visión 
de cómo debería ser regulada la sociedad, que se dio a partir de la contribución que hicieron las obras de Nozick, Friedman y von Hayek. Por lo tanto, estas oscilaciones puede decirse que son parte de la dinámica de reconfiguración histórica de nuestro imaginario político y de las interpretaciones que hacemos del mismo.

La imaginación política, entendida como imaginación contrafáctica, es la que permite anticipar cómo sería nuestra vida con los otros ciudadanos bajo un cierto gobierno o diseño institucional; su ejercicio nos permite revisar las diferentes posibilidades que tenemos para ello, los mejores caminos para lograrlo y las posibles consecuencias que se seguirían de eventuales modificaciones, y en virtud de esto es que oficia de posibilitadora de la racionalidad política. Estas modificaciones no suponen una transformación radical, sino que simplemente pueden consistir en la aplicación de una regla o principio ya institucionalizado a una nueva población o bajo una nueva modalidad. En medidas tan elementales y cotidianas como estas se ejerce nuestra imaginación política, al igual que en transformaciones más sustantivas y hasta revolucionarias. En estos últimos casos la incidencia que tienen las teorías políticas que a lo largo de la historia se han formulado es, como ya se señaló, altamente significativa, ya que penetran progresivamente nuestra forma de entender nuestra vida práctica y de esa forma contribuyen a su reconfiguración; ejemplos como los del pensamiento utópico (Broncano, 2009: 251-256; Acosta, 2017), Hobbes, Locke, Rousseau, Montesquieu o Marx, al igual que más recientemente John Rawls, han sido determinantes para la forma que tenemos de comprender nuestra vida práctica moderna y muy especialmente cómo debería ser el orden institucional que nos regula.

\section{IMAGINACIÓN LEGAL}

La imaginación legal tiene como función la representación de los individuos como sujetos de derecho y a partir de ello de las protecciones externas y de los límites que son necesarios para la realización de los fines. Este tipo de imaginación tiene por una parte un vínculo con la imaginación moral porque la idea de sujeto de derecho es concebida a partir de la condición de fines en sí mismos de los individuos, ya que solamente en virtud de que es posible la representación de un espacio individual como no sujeto a ningún tipo de interferencia externa es que podemos concebir las restricciones y los límites requeridos para llevar adelante nuestros fines. Por otra parte, la imaginación legal también tiene un vínculo con la imaginación política, y en particular con los imaginarios políticos ya que es a 
partir de ellos que se vislumbran las protecciones y los límites mencionados como justificables, a través de las medidas institucionales que permiten realizarlos.

Los imaginarios sociales, en tanto comprensiones compartidas que ofician de trasfondo a la imaginación legal han sido especialmente moldeados por la contribución que han hecho a los mismos las teorías del derecho natural. La condición de igualdad de los individuos reside en una idea de dignidad atribuida universalmente, que rompe con formas de atribuirla a partir de jerarquías o de diferencias de status que puedan afectar esta igualdad básica. Al igual que en el caso de la imaginación política, la influencia de las teorías que contribuyen a delinear la autocomprensión inherente al imaginario social que da cuenta de nuestra condición de sujetos de derecho, tiene un protagonismo altamente significativo y en tal sentido es claramente asimétrico con respecto a la imaginación ética y moral, en las que la teoría llega después que los individuos han establecido sus pautas de comportamiento, y sistematiza, ajusta o refuerza la forma en que entendemos cómo llevar adelante nuestra vida buena o actuar moralmente. En la imaginación legal, en cambio, la teoría llega primero, incide y transforma el imaginario social de tal forma que opera guiando nuestro comportamiento. El concebirnos como sujetos de derecho a partir de nuestra condición de iguales, y que ello sea algo que no puede sernos retaceado bajo ninguna circunstancia debido a que tal igualdad se basa en la dignidad que todos tenemos y que no solamente es atributo de unos pocos, es el resultado de las distintas teorías que han anticipado estos aspectos y nos han "forzado" a verlos como parte de nuestro horizonte. Estas teorías pueden ser entendidas más que como legales, como morales y políticas, es decir, el imaginario legal, como ya se indicó, se nutre de estas dos vertientes que tienen a la igual dignidad como elemento en el que basar las restricciones a las posibles interferencias externas, y los posibles diseños de las instituciones sociales requeridos para ello.

La perspectiva moral que alimenta al imaginario legal puede ser remitida a la idea de dignidad kantiana, como algo que no puede serle retaceado a ningún individuo. La coincidencia en este punto también se presenta en Locke, quien en su teoría justifica la limitación del poder del gobierno, a partir de una idea de igualdad fundada en los derechos de los individuos y que tiene como rasgo distintivo la posibilidad de que sean invocados contra el poder; a su vez, el marco institucional que se justifica consiste no en un acuerdo original a partir del cual fundar tales instituciones gubernamentales, sino en un proceso permanente en el que a partir de los derechos de los individuos el acuerdo debe ser ganado, en particular para establecer impuestos. Por su parte, las protecciones externas que aseguran la condición de sujeto de derecho no podrían ser adecuadamente concebidas si no 
se pudiese apelar a la autoridad del Estado, por lo tanto, el trasfondo hobbesiano sin el cual no sería posible concebir tal condición sin que el Estado tuviese el monopolio de la fuerza, complementa el requerimiento de que las instituciones aseguren las protecciones externas a los fines de los individuos.

Esta forma de teorizar la igualdad a partir de la dignidad inherente a todos los seres humanos y de las restricciones externas y limitaciones que surgen a partir de esta idea y que son realizadas a través de las instituciones sociales, contribuye en forma estructurante a la constitución del imaginario legal y a partir de él al ejercicio de la imaginación legal. Como ya se indicó, tanto las autocomprensiones que pautan cómo nos representamos como sujetos morales, como las que lo hacen con nuestra condición de ciudadanos, son dos formas de especificar la imaginación práctica que contribuye a representarnos como sujetos de derecho, siendo tal representación lo distintivo de la imaginación legal. Por lo tanto, la tradición de las sociedades y cómo han procesado la forma de asegurar la condición de sujetos de derecho a través de las instituciones permite el ejercicio de la imaginación legal, anticipando contrafácticamente, cuáles deberían ser los arreglos institucionales necesarios para estipular las protecciones externas y los límites requeridos para perseguir los fines vitales de los individuos, y en virtud de ello evaluar los actuales, someterlos a crítica, y eventualmente reconfigurarlos o transformarlos. La imaginación legal, entonces, se ejerce a través de una relación interna con una comprensión compartida de lo que significa ser sujeto de derecho y eso tiene una continuidad histórica que brinda el marco desde donde procesar públicamente lo que eso significa, y a partir de ello realizar las evaluaciones, críticas y eventuales reconfiguraciones de los diseños institucionales que permiten garantizar tal condición. Proyectando la relación entre imaginación práctica y racionalidad práctica al campo específico de lo legal, la imaginación legal al anticipar las posibles reconfiguraciones institucionales que especifican las protecciones externas y los límites que son necesarios para la realización de los fines de los individuos articula las bases para el intercambio de razones que justificará el marco institucional o su eventual reconfiguración para asegurar la condición de sujeto de derecho.

\section{CONCLUSIÓN}

La imaginación práctica entendida como nuestra capacidad para representar lo que se encuentra ausente, y en particular para anticipar contrafácticamente estados de cosas posibles, articula nuestra vida práctica en la medida en que hace posible el ejercicio de la racionalidad práctica. Si bien tenemos formas diferenciales de ejercer la imaginación en función de 
los contextos prácticos de los que se trate, en todos ellos oficia de posibilitadora del ejercicio reflexivo que permite adoptar razones con las que justificar nuestras posiciones al anticipar contrafáticamente los posibles cursos de acción y los escenarios a los que nos conducirían nuestras acciones. La anticipación de posibles escenarios que no están presentes y que son un posible futuro hace que la imaginación tome parte en la deliberación, y de esa forma tiene un rol articulador en la elección deliberada y reflexiva de los mejores medios necesarios para realizar los fines vitales que articulan lo que alguien considera como su buena vida. A su vez, este ejercicio de imaginación permite realizar el experimento mental que subyace a la adopción del punto de vista universal distintivo de los juicios morales, o las perspectivas que posibilitan anticipar, criticar o reconfigurar las instituciones sociales que aseguran la condición de igual ciudadanía o de sujeto de derecho. De esta forma la imaginación posibilita el ejercicio de la racionalidad práctica entendida como la adopción reflexiva de razones que permiten justificar en procesos intersubjetivos las posiciones adoptadas por un individuo.

Este rol determinante que tiene la imaginación práctica para el ejercicio de la racionalidad práctica constituye la principal justificación para su estímulo y protección a través de las instituciones sociales, ya que sin un ejercicio suficiente de ella difícilmente podamos contar con sujetos capaces de ejercer su condición de agentes y muy especialmente su autonomía personal, moral, política y legal.

\section{REFERENCIAS}

-Acosta, Y. (2017). Utopía. En C. Pereda (Ed.), Diccionario de justicia (pp. 539-542). México: Siglo XXI.

-Aristóteles (1994). Acerca del alma. Madrid: Gredos.

-Baynes, K. (2001). Practical Reason, the "Space of Reasons", and Public Reason.

En W. Rheg y J. Bohman (Eds.), Pluralism and the Pragmatic Turn (pp. 53-85).

Cambridge, Massachusetts: The MIT Press.

-Broncano, F. (2009). La melancolía del ciborg. Barcelona: Herder.

-Byrne R. M. J. (2005). The Rational Imagination. How People Create Alternatives to Reality. Cambridge, Massachusetts: The MIT Press.

-Castoriadis, C. (2005). Los dominios del hombre. Las encrucijadas del laberinto. Barcelona: Gedisa.

-Forst, R. (2002). Contexts of Justice. Berkeley: Universidad de California Press. -Forst, R. (2007). The Right to Justification. New York: Columbia University Press. -Habermas, J. (2000). Del uso pragmático, ético y moral de la razón práctica. En Aclaraciones a la ética del discurso (pp. 109-126). Madrid: Trotta.

-Hume, D. (1992). Tratado de la naturaleza humana. Madrid: Tecnos. 
-Kant, I. (1990). Fundamentación de la metafísica de las costumbres. Madrid: EspasaCalpe.

-Kant, I. (1991). Antropología en sentido pragmático. Madrid: Alianza.

-Kant, I. (2010). Crítica de la razón pura. Madrid: Gredos.

-Korsgaard, C. (2008). The Normativity of Instrumental Reason. En C. Korsgaard, The Constitution of Agency. Essays on Practical Reason and Moral Psychology (pp. 27-68), Oxford: Oxford University Press.

-Mackenzie, C. (2000). Imagining Oneself Otherwise. En C. Mackenzie \& N. Stoljar (Eds.), Relational Autonomy: Feminist Perspectives on Autonomy, Agency and the Social Self (pp. 124-150). Oxford: Oxford University Press.

-McMullen, M. N. \& Markman, K. D. (2002). Affective impact of close counterfactuals. Implications of possible futurs for possible pasts. Journal of Experimental Social Psychology, (38)1, 64-70.

-Pereira, G. (2013). Elements of a Critical Theory of Justice. Basingstoke: PalgraveMacmillan.

-Platón (1985). Diálogos V. Parménides, Teeteto, Sofista, Político (pp. 173-317 (Teeteto); pp. 331-482 (Sofista)). Madrid: Gredos.

-Rawls, J. (2001). Lecciones sobre la historia de la filosofía moral. Barcelona. Paidós.

-Stalnaker, R. (1984). Inquiry. Cambridge, Massachussets: The MIT Press.

-Tetlock, P. E. \& Parker G. (2005). Counterfactual thought experiments. Why we cannot live without them and how we can learn to live with them. En P. E. Tetlock, R. N. Lebow \& G. Parker (Eds.), Unmaking the West: Counterfactuals, Contingency, and Causations (pp. 3-35). Ann Arbor: University of Michigan Press.

Sumario: 1. Imaginación práctica como imaginación contrafáctica; 2. Imaginación ética; 3. Imaginación moral; 4. Imaginación política; 5. Imaginación legal; Conclusión; Referencias. 